\title{
GERMINAÇÃO IN VITRO DE GRÃOS DE PÓLEN EM Passiflora suberosa L. PARA SUA UTILIZAÇÃO EM HIBRIDAÇÃO INTERESPECÍFICA ${ }^{1}$
}

\author{
THYANE VIANA CRUZ², MARGARETE MAGALHÃES SOUZA ${ }^{3}$, FRANCISVALDO AMARAL ROZA², \\ AMÉRICO JOSÉ CARVALHO VIANA², GABRIELA DE OLIVEIRA BELO², JOSEFA WILMADOS SANTOS FONSECA²
}

RESUMO-Com o objetivo de avaliar a performance polínica de Passiflora suberosa, realizou-se a análise de germinação in vitro em grãos de pólen de plantas mantidas em casa de vegetação nas condições de Ilhéus, sul da Bahia, coletados em diferentes horários após a antese. A análise estatística foi realizada no delineamento inteiramente ao acaso, com seis tratamentos que consistiram de horários de coleta, de 7 às $17 \mathrm{~h}$. O meio de germinação foi o recomendado para o maracujazeiro-amarelo, e as lâminas foram incubadas a $28^{\circ} \mathrm{C}\left( \pm 1^{\circ} \mathrm{C}\right)$. Houve diferença significativa $(\mathrm{P}<0.01)$ entre os seis horários testados. O percentual médio de germinação do pólen foi negativamente influenciado pelo número de horas após a antese. Os maiores índices de germinação foram obtidos no período entre 7 e 9 h.

Termos para indexação: Passifloraceae, maracujazinho-cortiça-preto, pólen, performance polínica, planta ornamental.

\section{IN VITRO GERMINATION OF POLLEN GRAINS IN Passiflora suberosa L. FOR ITS USE IN INTERSPECIFIC HYBRIDIZATION}

ABSTRACT- In order to evaluate the pollen performance of Passiflora suberosa, in vitro germination of pollen in plants grown on greenhouse at Ilhéus, South of Bahia, was studied. Statistical analysis was performed considering a randomized experimental design, with six treatments that consisted of collection times, from 7:00 to 5:00. The germination element was the same used for yellow passion fruit, and the slides were incubated at $28^{\circ} \mathrm{C}\left( \pm 1^{\circ} \mathrm{C}\right)$. There was a significant difference $(\mathrm{P}<0.01)$ among the six collect times tested, and among plants at 7:00 and 8:00, showing heterogeneity among the genotypes. The average percentage of pollen germination was negatively influenced by the later testing times. The greatest germination index was at 7:00 and 9:00.

Index terms: Passifloraceae, passion flower, pollen, pollen performance, ornamental plant.

\section{INTRODUÇÃO}

Os maracujazeiros pertencem ao gênero Passiflora L., havendo no Brasil mais de 150 espécies nativas (Hoehne, 1946), algumas inclusive endêmicas e ameaçadas de extinção (Guedes, 2002). Muitas espécies são utilizadas in natura por suas propriedades medicinais e por seus frutos comestíveis (Sousa \& Meletti, 1997). Porém, muitas delas são apreciadas no mundo inteiro por seu valor ornamental, sendo suas sementes amplamente comercializadas, principalmente na América do Norte e Europa (Ulmer \& MacDougal, 2004). As flores de Passiflora são consideradas exóticas e complexas, algumas de coloração forte e brilhante, e outras de coloração suave e marcante devido, principalmente, à presença da corona, que caracteriza a família Passifloraceae. Igualmente fascinante é a ampla variedade de formatos de folhas dentro do gênero, e muitas espécies possuem valor ornamental somente em função da folhagem (Souza et al., 2003). Plantas híbridas, no entanto, têm maior valor no mercado de ornamentais (Ulmer \& MacDougal, 2004).

Passiflora suberosa L. ou maracujazinho-cortiçapreto é uma espécie tropical, pan-americana (Sousa \& Meletti, 1997), ocorrendo no oeste da Índia, em muitas partes do México e nas Américas Central e do Sul (Ulmer \& MacDougal, 2004), além do Hawaii, New Guinea, Fiji e Samoa e Ilhas Galápagos (Vanderplank, 2000). Caracteriza-se como trepadeira de pequeno porte, que apresenta pequenas flores amarelo-esverdeadas ou verdes-claras que surgem solitárias ou em pares nas axilas das folhas, podendo apresentar um opérculo vermelho, medindo 1,3 a 2,5 cm de diâmetro, com cinco sépalas e destituídas de pétalas (o que caracteriza a secção Cieca (Medic.) Mast. do subgênero Plectostemma Mast.), com 1 - 2 brácteas ou podem ser ausentes, com duas séries de corona; frutos pequenos, ovóides ou globosos, com 0,6 a 1,5 cm de diâmetro e de cor roxa; folhas de forma extremamente variada, usualmente polimórficas no mesmo indivíduo, podendo variar de inteiras a profundamente trilobadas, com duas glândulas no pecíolo; caule estriado e, quando adulto, revestido de grossa casca suberosa, ou seja, corticosa (Sousa \& Meletti, 1997; Ulmer \& MacDougal, 2004), que faz a planta tolerar temperaturas bem mais baixas, até leves congelamentos (Vanderplank, 2000). A extrema variabilidade da espécie resulta em vasta sinonímia com mais de sessenta denominações (Sousa $\&$ Meletti, 1997).

P. suberosa floresce praticamente o ano inteiro (Ulmer $\&$ MacDougal, 2004), com a abertura das flores ocorrendo antes das 7 h da manhã (Souza et al., 2005a). Devido às suas características, pode ser utilizada em hibridações para obtenção

${ }^{1}$ (Trabalho 020-08). Recebido em: 08-01-2008. Aceito para publicação em: 19-09-2008. A pesquisa é parte integrante da Iniciação Científica da primeira autora, na Universidade Estadual de Santa Cruz (UESC).

${ }^{2}$ Agrônomos, UESC.

${ }^{3}$ Bióloga, Professora, Dra. do Departamento de Ciências Biológicas/UESC - Rod. Ilhéus-Itabuna, Km 16, CEP-45662-000, Ilhéus-BA. souzamagg@yahoo.com.br. 
de plantas de pequeno porte e com flores e frutos coloridos para decoração de interiores, e sua utilização para ornamentação e para produção de híbridos ( $P$. 'Curiosa' $[P$. suberosa $\mathrm{x} P$. coriacea $]$ S. Kamstra; $P$. 'Ivy Waves' [P. suberosa x $P$. coriacea $=4 \mathrm{n}] \mathrm{R}$. Knight) é reconhecida (Ulmer \& MacDougal, 2004; Vanderplank, 2000).

Nessa espécie, há variação no nível de ploidia (número básico $x=6$; Melo et al., 2001), com espécimes diplóides $2 n=12$ (Stebbins, 1950) e poliplóides com $2 n=24$ e $2 n=36$ (Storey, 1950). Estudos recentes indicaram ser esta espécie autocompatível (Ulmer \& MacDougal, 2004; Souza et al., 2005b), ao contrário de algumas espécies desse gênero (Bruckner et al., 1995). Apesar de autocompatível, provavelmente $P$. suberosa necessita de um polinizador devido à morfologia floral e características dos grãos de pólen das passifloras, pesados e pegajosos, o que não permite a polinização pelo vento (Amela Garcia \& Hoc, 1997). Quanto ao relacionamento evolutivo de Passiflora com as borboletas Heliconiinae, P. suberosa é considerada hospedeira de Heliconius charitonia, a qual se utiliza de seu pólen e néctar como fonte de amino ácidos e suprimentos, e de suas folhas para a postura de ovos (Ulmer \& MacDougal, 2004). Porém, o polimorfismo foliar que a planta apresenta no seu início de desenvolvimento é considerado uma defesa contra ataques, uma vez que as mudanças nos formatos das folhas não seriam reconhecidas pelo predador (Vanderplank, 2000).

Visando à utilização dessa espécie como genitora em hibridações interespecíficas e, conseqüentemente, a maximização da taxa de pegamento resultante desses cruzamentos, iniciou-se com este trabalho a análise da performance polínica via germinação in vitro. Espera-se conhecer o melhor horário para realização de polinizações cruzadas envolvendo $P$. suberosa como doadora de pólen.

\section{MATERIAL E MÉTODOS}

O experimento foi realizado em plantas de Passiflora suberosa, $2 n=24$ (Souza, 2002), propagadas por sementes, que fazem parte do Banco Ativo de Germoplasma (BAG-Passifloras) mantido no Câmpus da UESC. O delineamento experimental utilizado foi o inteiramente ao acaso, com quatro repetições (plantas) e seis tratamentos. Os tratamentos consistiram de seis horários de coleta, a partir do horário de abertura da flor até o seu fechamento (de 7 às $17 \mathrm{~h}$ ), em intervalos de duas horas. Os botões florais foram protegidos com sacos de papel colocados um dia antes da abertura da flor. O teste de germinação foi realizado conforme descrito para a espécie cultivada $P$. edulis f. flavicarpa (Bruckner et al., 2000), que foi utilizada como controle. Uma antera/ flor/planta/horário foi coletada, e os grãos de pólen (GP) foram depositados em uma gota de meio de germinação composto de $0,10 \mathrm{~g} / \mathrm{L}$ de $\mathrm{H}_{3} \mathrm{BO}_{3} ; 50 \mathrm{~g} / \mathrm{L}$ de sacarose; $0,3 \mathrm{~g} / \mathrm{L} \mathrm{de} \mathrm{Ca}\left(\mathrm{NO}_{3}\right)_{2} .4 \mathrm{H}_{2} \mathrm{O}$; $0,2 \mathrm{~g} / \mathrm{L}$ de $\mathrm{MgSO}_{4} .7 \mathrm{H}_{2} \mathrm{O}$ e $0,1 \mathrm{~g} / \mathrm{L}$ de $\mathrm{KNO}_{3}$, previamente autoclavado a $121^{\circ} \mathrm{C}$, por 15 minutos. Para evitar que o tubo polínico se soltasse do GP durante as análises, foram testados os seguintes procedimentos de incubação: a) lâmina escavada com lamínula; b) lâmina escavada com lamínula em câmara úmida; c) lâmina comum com lamínula; d) lâmina comum com lamínula em câmara úmida. O material foi mantido em estufa com temperatura de $28 \pm 1^{\circ} \mathrm{C}$, por até $24 \mathrm{~h}$ de incubação. Considerouse como GP germinados aqueles cujo tubo polínico apresentou comprimento mínimo duas vezes maior que o diâmetro médio do GP. Os dados foram submetidos à ANOVA e de regressão, com auxílio do programa computacional GENES (Cruz, 2001).

\section{RESULTADOS E DISCUSSÃO}

Foram obtidos índices muito baixos de germinação in vitro (GIV) para P. suberosa (Fig. 1A), enquanto para o maracujazeiro-amarelo, $P$. edulis f. flavicarpa, utilizado como controle, o resultado foi de quase $100 \%$ de germinação (Fig. 1B). Embora Bruckner et al. (2000) tenham utilizado com sucesso placas de petri para incubar os grãos de pólen (GP), em P. suberosa foi necessário adaptar a metodologia, uma vez que os tubos polínicos se soltavam dos GP facilmente. Assim, o melhor método para incubação foi alcançado utilizando-se de uma gota do meio com os GP entre lâmina sem escavação e lamínula, para diminuir o impacto do movimento de transporte da estufa ao microscópio, e em câmara úmida, para evitar a evaporação do meio, sendo este o único método utilizado para a contagem dos GPs germinados. Utilizando este procedimento, foi observado que $90 \%$ dos GP se mantiveram associados aos seus tubos polínicos durante o procedimento de contagem, enquanto utilizando os demais procedimentos, mais de $50 \%$ dos tubos polínicos encontravamse soltos no meio de germinação, não sendo utilizados para análise.

Os resultados de GIV em $P$. suberosa são apresentados nas Tabelas I e II, e foram, em média: a) $7 \mathrm{~h}-21,8 \%$; b) $9 \mathrm{~h}-7,8 \%$; c) $11 \mathrm{~h}-7,8 \%$; d) $13 \mathrm{~h}-3,6 \%$; e) $15 \mathrm{~h}-2,8 \%$;f) $17 \mathrm{~h}-2,7 \%$. Pela análise de variância, houve diferença significativa $(\mathrm{P}<0.01)$ entre os seis horários testados. O percentual de germinação dos grãos de pólen foi negativamente influenciado pelo número de horas após a antese ( $Y^{\prime}=15,913-1,639 x ; R^{2}=0,7063 ;$ Fig. 2). Houve relação linear entre o percentual de germinação in vitro $(\mathrm{Y})$ e o número de horas após a antese (X), com a maior média de germinação obtida às $7 \mathrm{~h}$, e a mais baixa às $17 \mathrm{~h}$, ou seja, com tendência de queda de percentual durante o tempo de abertura da flor.

A perda da viabilidade polínica em função do tempo de abertura da flor foi observada no maracujazeiro-amarelo (Souza et al., 2002), utilizando-se de análise histoquímica, porém o índice ainda manteve-se alto, superior a $75 \%$, mesmo 24 h após a antese. Analisando a viabilidade polínica em espécies silvestres de Passiflora com testes histoquímicos (solução de Alexander e lugol) e com polinizações in vivo, foram detectados altos percentuais de viabilidade em pólen obtido de flores recémabertas, entre 78,22 a 99,55\% (Souza et al., 2004), dentre eles o de P. suberosa, com $97,07 \%$ de viabilidade polínica verificada com teste histoquímico e $100 \%$ de pegamento nos testes de polinização in vivo, mesmo quando realizados às $17 \mathrm{~h}$. Esses resultados são bastante contrastantes quando comparados com o obtido da germinação in vitro, $21,82 \%$, logo nos primeiros momentos de abertura da flor.

Em muitas espécies, a esterilidade do pólen pode estar 
associada com irregularidades meióticas, tais como citomixia (Caetano-Pereira \& Pagliarini, 1997) e mixoploidia (Caetano-Pereira et al., 1998) em milho, anormalidades na formação do fuso em Centella asiatica (Consolaro et al., 1996), baixa freqüência de quiasmas em espécies de Lycopersicon (Haroun, 1996), segregação irregular de univalentes em espécies de Pennisetum (Dujardin \& Hanna, 1984) e em Aptenia cordifolia (Pagliarini, 1990). Em variedades de soja, a inviabilidade polínica tem sido relacionada a anormalidades meióticas (Bione et al., 2000).

Fatores ambientais também podem interferir na viabilidade polínica. Quando a abertura da antera coincide com elevada umidade do ar, a alta pressão osmótica do conteúdo celular do
GP, aliada à baixa resistência de sua parede diminuem a viabilidade polínica (Sousa, 1994). Estudos em outras espécies têm demonstrado que botões florais são particularmente sensíveis a estresse por aquecimento num estágio de 3 a 5 dias antes da abertura da antese, causando redução na produção e viabilidade dos GP (Vara Prasad et al., 1999).

Os estudos de razão pólen:óvulo em P. suberosa indicaram que essa espécie produz um número de grãos de pólen 83 vezes maior que o número de óvulos (Souza et al., 2005b). Essa característica, aliada ao fato de que essa espécie é autocompatível são as responsáveis pela baixa performance de o pólen não prejudicar a frutificação em $P$. suberosa.

TABELA 1- Germinação in vitro em Passiflora suberosa, de grãos de pólen (GP) coletados em diferentes horários após a antese (7h).

\begin{tabular}{|c|c|c|c|c|c|c|c|c|c|c|c|c|c|}
\hline \multirow{2}{*}{$\begin{array}{l}\text { Horário } \\
\text { de coleta }\end{array}$} & \multirow{2}{*}{$\begin{array}{l}\mathrm{N}^{\circ} \text { de horas } \\
\text { após antese }\end{array}$} & \multicolumn{3}{|c|}{ Planta 1} & \multicolumn{3}{|c|}{ Planta 2} & \multicolumn{3}{|c|}{ Planta 3} & \multicolumn{3}{|c|}{ Planta 4} \\
\hline & & $\begin{array}{l}\mathrm{N}^{\circ} \mathrm{GP} \\
\text { Germ. }\end{array}$ & $\begin{array}{c}\text { Total } \\
\text { Contado } \\
\end{array}$ & $\begin{array}{l}\% \text { GP } \\
\text { Germ. }\end{array}$ & $\begin{array}{l}\mathrm{N}^{\circ} \mathrm{GP} \\
\text { Germ. }\end{array}$ & $\begin{array}{c}\text { Total } \\
\text { Contado } \\
\end{array}$ & $\begin{array}{l}\% \text { GP } \\
\text { Germ. }\end{array}$ & $\begin{array}{l}\mathrm{N}^{\circ} \mathrm{GP} \\
\text { Germ. }\end{array}$ & $\begin{array}{c}\text { Total } \\
\text { Contado }\end{array}$ & $\begin{array}{l}\% \text { GP } \\
\text { Germ. }\end{array}$ & $\begin{array}{l}\mathrm{N}^{\circ} \mathrm{GP} \\
\text { Germ. }\end{array}$ & $\begin{array}{c}\text { Total } \\
\text { Contado } \\
\end{array}$ & $\begin{array}{l}\% \text { GP } \\
\text { Germ. }\end{array}$ \\
\hline 7 horas & 0 & 304 & 1.091 & 21,8 & 402 & 1.630 & 24,6 & 305 & 1.525 & 20,0 & 304 & 1.451 & 20,9 \\
\hline 9 horas & 02 & 98 & 1.280 & 7,6 & 102 & 1.389 & 7,3 & 87 & 1.395 & 6,2 & 113 & 1.141 & 9,9 \\
\hline 11 horas & 04 & 117 & 1.368 & 8,5 & 122 & 1.427 & 8,5 & 81 & 1.294 & 6,2 & 118 & 1.499 & 7,8 \\
\hline 13 horas & 06 & 38 & 1.235 & 3,0 & 57 & 1.376 & 4,1 & 53 & 1.492 & 3,5 & 51 & 1.344 & 3,7 \\
\hline 15 horas & 08 & 31 & 1.210 & 2,5 & 43 & 1.553 & 2,7 & 55 & 1.384 & 3,9 & 19 & 1.203 & 1,5 \\
\hline 17 horas & 10 & 22 & 1.096 & 2,0 & 42 & 1.149 & 3,6 & 28 & 1.036 & 2,7 & 38 & 1.328 & 2,8 \\
\hline
\end{tabular}

TABELA 2 - Média, desvio-padrão (DP), coeficiente de variação (CV) e variância da percentagem de germinação in vitro de pólen em quatro plantas de Passiflora suberosa, coletado em diferentes horários após a antese (7h).

\begin{tabular}{ccccccc}
\hline $\begin{array}{c}\text { Horário de } \\
\text { coleta }\end{array}$ & $\begin{array}{c}\mathrm{N}^{\circ} \text { de horas } \\
\text { após antese }\end{array}$ & $\begin{array}{c}\text { Horário de } \\
\text { coleta }\end{array}$ & Média & Desvio-padrão & CV & Variância \\
\hline 7 horas & 0 & 7 horas & $\mathbf{2 1 , 8 2}$ & 1,9906 & 9,1207 & 3,9625 \\
9 horas & 02 & 9 horas & $\mathbf{7 , 7 5}$ & 1,5546 & 20,0589 & 2,4167 \\
11 horas & 04 & 11 horas & $\mathbf{7 , 7 5}$ & 1,0847 & 13,9967 & 1,1767 \\
13 horas & 06 & 13 horas & $\mathbf{3 , 5 7}$ & 0,4573 & 12,7929 & 0,2092 \\
15 horas & 08 & 15 horas & $\mathbf{2 , 6 5}$ & 0,9849 & 37,1655 & 0,97 \\
17 horas & 10 & 17 horas & $\mathbf{2 , 7 7}$ & 0,6551 & 23,6075 & 0,4292 \\
\hline
\end{tabular}

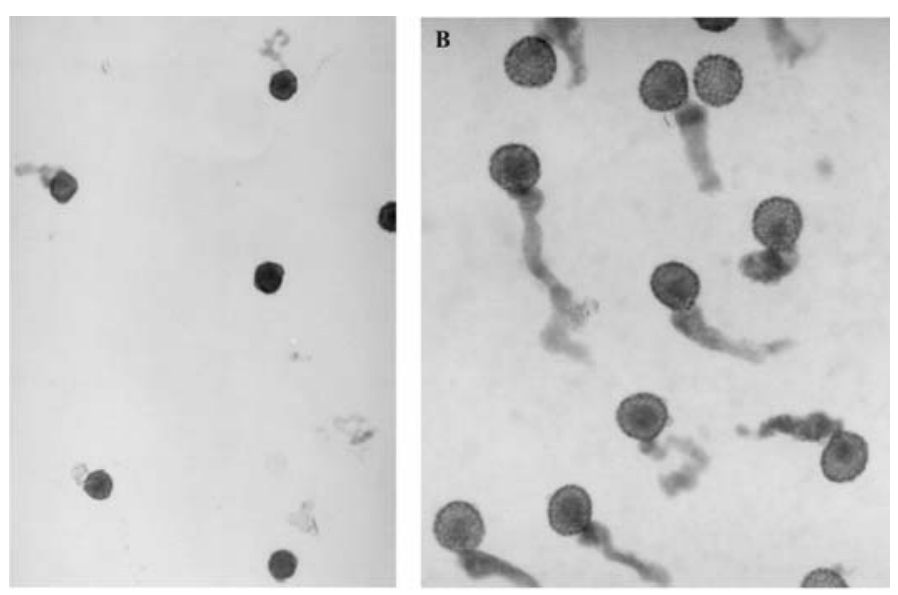

FIGURA 1- Germinação in vitro de grãos de pólen. A - Passiflora suberosa; B - Passiflora edulis f. flavicarpa. 


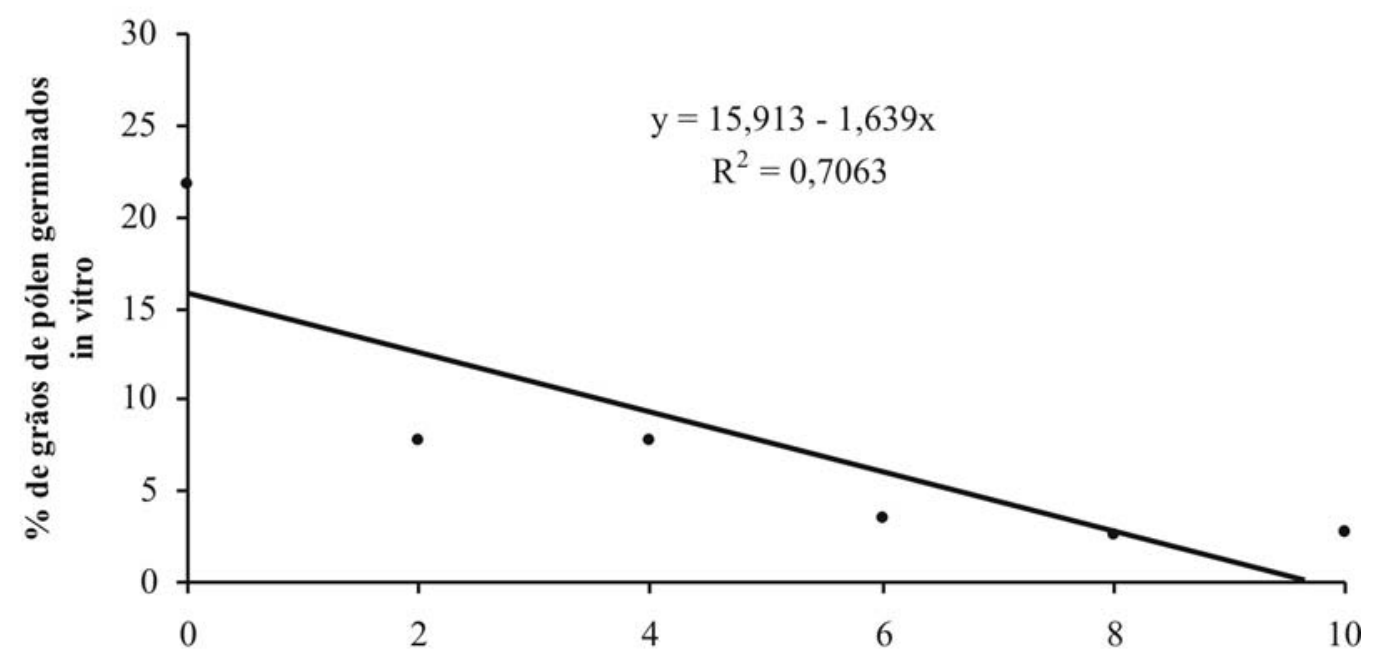

FIGURA 2- Germinação in vitro de grãos de pólen em Passiflora suberosa, coletados em diferentes horários após a antese (7h).

\section{CONCLUSÃO}

De acordo com o teste de germinação in vitro, o percentual médio de germinação do pólen em $P$. suberosa foi negativamente influenciado pelo número de horas após a antese. Os maiores índices de germinação foram obtidos logo após a antese, no período entre 7 e $9 \mathrm{~h}$.

\section{AGRADECIMENTOS}

Agradecemos à FAPESB, pelo apoio financeiro.

\section{REFERÊNCIAS}

AMELA GARCIA, M.T.; HOC, P.S. Floral biology and reproductive system of Passiflora caerulea (Passifloraceae). Beitrage zur Biologie der Pflanzen, Berlin, v.70, p.1-20, 1997.

BIONE, N.C.P.; PAGLIARINI, M.S.; TOLEDO, J.F.F. Meiotic behavior of several Brazilian soybean varieties. Genetics and Molecular Biology, Ribeirão Preto, v.23, p.423-631, 2000.

BRUCKNER, C.H.; CASALI, V.W.D.; MORAES, C.F.; REGAZZI, A.J.; SILVA, E.A.M. Self-incompatibility in passion fruit (Passiflora edulis Sims). Acta Horticulturae, The Hague, v.370, p.45-57, 1995.

BRUCKNER, C.H.; SILVA, M.M.; FALLEIRO, T.M.;ANDRADE, B.B.; MOREIRA, A.E. Viabilidade do pólen de maracujazeiro sob diferentes condições de armazenamento. Revista Ceres, Viçosa, v.47, p.523-531, 2000 .
CAETANO-PEREIRA, C.M.; PAGLIARINI, M.S. Cytomixis in maize microsporocytes. Cytologia, Tokyo, v.62, p.351-355, 1997.

CAETANO-PEREIRA, C.M.; TASCHETTO, O.M.; PAGLIARINI, M.S.; BRASIL, E.M. Spontaneous mixoploidy in maize anthers. Cytologia, Tokyo, v.63, p.305-309, 1998.

CONSOLARO, M.E.; PAGLIARINI, M.S.; CHAVES, L.J. Meiotic behavior, pollen fertility and seed production in Brazilian populations of Centella asiatica (L.) Urban (Umbelliferae). Cytologia, Tokyo, v.61, p.375-381, 1996.

CRUZ, C.D. Programa Genes versão Windows: aplicativo computacional em genética e estatística. Viçosa: Editora UFV, 2001.648p.

DUJARDIN, M.; HANNA, W. Microsporogenesis, reproductive behavior, and fertility in five Pennisetum species. Theoretical and Applied Genetics, Berlin, v.67, p.197-201, 1984.

GUEDES, A. Bromélias e orquídeas com vista para o mar. Ciência Hoje, São Paulo, v.30, p.46-49, 2002.

HAROUN, S.A. Chromosome association and pollen fertility of parental and interespecific hybrids of Lycopersicon esculentum X L. hirsutum and L. pennellii. Genetica, Dordrecht, v.98, p.103106, 1996.

HOEHNE, F.G. Frutas indígenas. São Paulo: Instituto de Botânica, 1946. 88p.

PAGLIARINI, M.S. Meiotic behavior and pollen fertility in Aptenia cordifolia (Aizoaceae). Caryologia, Firenze, v.43, p.157$162,1990$. 
SOUSA, P.J.S. Polinização em maracujazeiro. In: SÃO JOSÉ, A.R. (Ed.). Maracujá: produção e mercado. Vitória da Conquista: UESB, 1994. p. 65-70.

SOUSA, J.S.I.; MELETTI, L.M.M. Maracujá: espécies, variedades e cultivos. Piracicaba: Editora FEALQ, 1997. 179p.

SOUZA, M.M. Estudos genômicos e reprodutivos em espécies de Passiflora. 2002. 162 f. Tese (Doutorado) - Centro de Ciências e Agrotecnologia Agropecuária, Universidade Estadual do Norte Fluminense Darcy Ribeiro (UENF), Campos dos Goytacazes-RJ, 2002.

SOUZA, M.M.; PEREIRA, T.N.S.; MARTINS, E.R. Microsporogênese e microgametogênese associadas ao tamanho do botão floral e da antera e viabilidade polínica em maracujazeiroamarelo (Passiflora edulis Sims f. flavicarpa Degener). Ciência e Agrotecnologia, Lavras, v.26, p.1209-1217, 2002.

SOUZA, M.M.; PEREIRA, T.N.S. Passifloras como plantas ornamentais. In: CONGRESSO BRASILEIRO DE FLORICULTURA E PLANTAS ORNAMENTAIS, 14., CONGRESSO BRASILEIRO DE CULTURA DE TECIDOS DE PLANTAS, 1., 2008, Lavras. Anais... Lavras: UFLA/FAEPE, 2003. p.24.

SOUZA, M.M.; PEREIRA, T.N.S.; VIANA, A.P.; SILVA, L.C.; SUDRÉ, C.P. Pollen viability and fertility in wild and cultivated Passiflora species (Passifloraceae). Beitrage zur Biologie der Pflanzen, Berlin, v.73, p.1-18, 2004.
SOUZA, M.M.; BELO, G.O.; FONSÊCA, J.W.S.; VIANA, A.J.C.; CRUZ, T.V.; SOPRANI JÚNIOR, G.G; ROZA, F.A.; PEREIRA, N.E.; SILVEIRA, A. Viabilidade polínica e receptividade do estigma em Passiflora suberosa por meio de testes histoquímicos como subsídio para hibridação interespecífica. In: CONGRESSO BRASILEIRO DE MELHORAMENTO DE PLANTAS, 3., 2005, Gramado. Anais... Passo Fundo: EMBRAPA Trigo/SBMP, 2005a. 1CD-ROM

SOUZA, M.M.; CRUZ, T.V.; FRANCO, M.A.M.; BELO; G.O.; FONSÊCA, J.W.S.; VIANA, A.J.C.; SOPRANI JÚNIOR, G.G.; ROZA, F.A.; PEREIRA, N.E.; SILVEIRA, A. Estudo do Sistema reprodutivo de Passiflora suberosa para fins de hibridação interespecífica. In: CONGRESSO BRASILEIRO DE MELHORAMENTO DE PLANTAS, 3. 2005, Gramado. Anais... Passo Fundo: EMBRAPA Trigo/SBMP, 2005b. 1 CD.

STEBBINS, G.L. Variation and evolution in plants. New York: Columbia University Press, 1950.

STOREY, W.B. Chromosome numbers of some species of Passiflora occurring in Hawaii. Pacific Science, Honolulu, v.4, p.37-42, 1950.

ULMER, T.; MACDOUGAL, J.M. Passiflora passionflowers of the world. Portland: Timber Press, 2004. 430p.

VANDERPLANK, J. Passion flowers. Cambridge: The MIT Press, 2000.224p.

VARA PRASAD, P.V.; CRAUFURD, P.Q.; SUMMERFIELD, R.J. Fruit number in relation to pollen production and viability in Groundnut exposed to short episodes of heat stress. Annals of Botany, London, v.84, p.381-386, 1999. 